\title{
Dossiê
}

\section{PESQUISAS SOBRE FORMAÇÃO DE PROFESSORES: DIFERENTES OLHARES, MÚLTIPLAS PERSPECTIVAS}

\author{
INVESTIGACIÓN SOBRE LA FORMACIÓN DE \\ PROFESORES: vistas diferentes, múltiples perspectivas
}
RESEARCH ON TEACHER TRAINING: different views, multiple perspectives

Maria de Fátima Barbosa Abdalla*

Júlio Emílio Diniz-Pereira**

https://doi.org/10.38117/2675-181X.formov2020.v2i2n4.336-359

Repensar a formação de professores, assim como sua carreira, condições de trabalho e salários, tem sido objeto de estudos, de pesquisas e de lutas, especialmente, nos dias de hoje, quando se tem que enfrentar desafios de toda ordem. Desafios estes que se inserem no contexto das transformações políticas, socioculturais e econômicas, que ocorrem nestes tempos tão difíceis de neoliberalismo e de pandemia. Neoliberalismo, que se traduz por um conjunto de práticas políticas e econômicas, que vem fortalecendo uma posição ideológica de direita, conservadora e privatista, e que esvazia o Estado de direito e a soberania popular, e adensa os cortes nas políticas sociais. E a pandemia, provocada pelo novo coronavírus, que vem agravar, ainda mais, este quadro de crise e de sofrimento social. Diante desse contexto, temos um (des) governo ${ }^{1}$, eleito com notícias falsas e com

\footnotetext{
${ }^{1}$ O governo de Jair Bolsonaro, a partir de janeiro de 2019, após o impeachment de Dilma Roussef, com o golpe de 2016, e a saída de Michel Temer, traz uma "onda conservadora" para o país, que, segundo Almeida (2019, p. 185-186), “[...] articula, em níveis diferentes, pelo menos, quatro linhas de forças sociais: economicamente liberal, moralmente reguladora, securitariamente punitiva e socialmente intolerante". Forças estas que retratam um "desgoverno", que se decompõe, ao mesmo tempo, que vai destruindo os espaços de interação política, muitas vezes, "fabricados" pelas mídias, na divulgação de fake news, e que colocam em crise o pacto democrático consagrado na Constituição de 1988, acentuando, ainda mais, os problemas econômicos, sociais, culturais, sanitários e de educação.
} 
o apoio de setores dominantes, que tenta nos afastar de conquistas obtidas desde a Constituição de 1988 (BRASIL, 1988), aprofundando, cada vez mais, as desigualdades sociais. O que evidencia um grave retrocesso e um panorama de incertezas que afetam também o cenário educacional do país.

$\mathrm{Na}$ esteira desses desafios, é que consideramos importante situar as resistências que temos que fazer no campo da educação e da formação de professores. E é, neste espaço, que consideramos necessário destacar, sobretudo, a luta histórica que a Associação Nacional pela Formação dos Profissionais de Educação (Anfope) tem realizado, durante as últimas décadas, por uma política global ${ }^{2}$ de formação de professores; assim como, por melhores condições para a formação e valorização dos profissionais de educação e pela escola pública em nosso país. Destacamos, ainda, sua resistência e sua persistência na organização de um movimento que vem constituindo um acúmulo de conhecimentos na direção de uma concepção de formação, que propicie uma articulação dialética entre os fundamentos teóricos, históricos, políticos e econômicos, dentre outros, e a prática social. Além disso, uma formação que coloque em perspectiva atender a uma educação laica, gratuita, referenciada socialmente, inclusiva e de justiça social, e que procure se pautar por "[...] resultados dos estudos dos pesquisadores que têm orientado os educadores, seus movimentos e entidades no debate sobre os princípios e fundamentos da formação" (FREITAS, 2007, p. 1207).

Buscando alternativas que procurem mostrar diferentes olhares e múltiplas perspectivas para as pesquisas sobre formação de professores, objetivo deste Dossiê, é que firmamos, neste primeiro momento, a necessidade de se evidenciar a criação e o movimento da Anfope em sua luta histórica no campo da formação de professores. A intenção aqui é de levantar algumas concepções e questões debatidas (ou combatidas) pela entidade frente às políticas educacionais, mais especificamente, às políticas de formação e de valorização dos profissionais da educação, que são postas e/ou impostas ao campo educacional, a fim de contribuir para a sua compreensão crítica.

A Associação ${ }^{3}$ foi criada, em 26 de julho de 1990, em Belo Horizonte (MG), durante o V Encontro Nacional da Comissão Nacional de Reformulação dos Cursos de Formação do Educador (ANFOPE, 1990), a partir de um movimento dos educadores,

\footnotetext{
${ }^{2}$ O Documento Final do IX Encontro Nacional, realizado em Campinas, em 1998, define que "[...] uma política global de formação de professores implica tratar, simultaneamente e com a mesma seriedade, a formação inicial, as condições de trabalho, salário e carreira e a formação continuada, na busca por uma educação pública e gratuita de qualidade, que garanta a inclusão das classes populares", na luta por uma "sociedade mais justa e igualitária" (ANFOPE, 1998, p. 22).

${ }^{3}$ A Anfope remonta sua origem ao Comitê Nacional Pró-Formação do Educador, instalado em 02/04/1980, durante a $1^{\text {a }}$ Conferência Brasileira de Educação (CBE), na PUC/SP. Este Comitê se configurou como Comissão Nacional de Reformulação dos Cursos de Formação do Educador (CONARCFE), criada em Belo Horizonte (1983), e que promoveu 5 encontros nacionais no período de 1983 a 1990 (ANFOPE, 2018).
} 
iniciado no final da década de 1970 , em meio à luta pela redemocratização do país. É preciso destacar que, em sua trajetória, foram consolidados princípios já defendidos, anteriormente, pelo movimento dos educadores, dentre eles, a Base Comum Nacional. Já, no $1^{\circ}$ Encontro Nacional da CONARCFE, que ocorreu em Belo Horizonte, de 21 a 25 de novembro de 1983. Ao se pensar nos cursos de formação, a Comissão indicou que "[...] as instituições deverão ter liberdade para propor e desenvolver experiências pedagógicas a partir de uma base comum nacional" (CONARCFE 4 , 1983, p. 4), entendendo que:

A base comum nacional dos Cursos de Formação de Educadores não deve ser concebida como um currículo mínimo ou um elenco de disciplinas, e sim como uma concepção básica da formação do educador e a definição de um corpo de conhecimentos fundamental. (CONARCFE, 1983, p. 4)

Também, é importante considerar, que outras concepções foram fazendo parte do ideário da Anfope, como, por exemplo, as concepções de docência e de educador, também debatidas neste mesmo Encontro. Nesta perspectiva a "docência constitui a base da identidade profissional de todo educador", e um dos papéis centrais do educador, que é ser um profissional que "domina determinado conteúdo técnico, científico e pedagógico que traduz o compromisso ético e político com os interesses da maioria da população brasileira" (CONARCFE, 1983, p. 4).

Mais adiante, no $2^{\circ}$ Encontro da CONARCFE, ocorrido em Goiânia, em agosto de 1986, entendeu-se que era preciso explicitar, melhor, a concepção da Base Comum Nacional, em seu significado e suas implicações, definindo-se, assim, três dimensões (CONARCFE, 1986), que, segundo a Comissão, estariam "intrinsicamente relacionadas", tal como registrado a seguir:

a) Dimensão profissional: que requer um corpo de conhecimentos que identifique toda a categoria profissional e, ao mesmo tempo, corresponda à especificidade de cada profissão. Como professores, devemos confluir num certo saber e num certo fazer;

b) Dimensão política: que aponta para a necessidade de que os profissionais formados pelas diversas licenciaturas sejam capazes de repensar e recriar a relação teoria-prática, o que só pode se dar se tiverem uma formação que permita uma visão globalizante das relações educação-sociedade e do papel do educador comprometido com a superação das desigualdades existentes;

\footnotetext{
${ }^{4}$ Este Documento da CONARCFE, assim como os demais documentos referentes aos dezenove Encontros Nacionais (de 1983 a 2018) estão disponíveis no site da Anfope: https://www.anfope.org.br/documentosfinais/.
} 
c) Dimensão epistemológica: que remete à natureza dos profissionais da escola, instituição social necessária à transmissão e à elaboração de um saber, em que o científico deve ter um espaço privilegiado. A base comum deve, portanto, fundamentar-se em uma estrutura científica capaz de romper com o senso comum, sem perder o núcleo de bom senso nele existente. (CONARCFE, 1986, p. 5, grifos nossos)

Diante dessas três dimensões - profissional, política e epistemológica - e tendo como fio condutor a docência como a base da identidade profissional, a Base Comum Nacional, segundo a Conarcfe (1986), deverá se caracterizar “[...] como a necessidade de formação de um profissional consciente de sua responsabilidade histórica, traduzida pela reflexão crítica da sociedade e da prática educativa [...]", e que seja comprometida "com a escola pública e com os reais interesses da classe trabalhadora" (CONARCFE, 1986, p. 5).

Como já mencionado, no ano de 1990, no quinto encontro da Conarcfe ${ }^{5}$ (1990), cria-se a Anfope, e, dentre outras colocações, retoma-se a concepção de Base Comum Nacional como questão conceitual, no entendimento de que o termo "base" significa "núcleo essencial da formação do profissional de educação", e que "[...] pode referir-se, por exemplo, à fundamentação que o conhecimento de outras áreas correlatas à educação fornece a esta" (CONARCFE, 1990, p. 5). O que envolve, também, “[...] o sentido de 'fundamentos' como estudo do status epistemológico da educação enquanto ciência, sua metodologia, campos de estudos e de aplicação" (CONARCFE, 1990, p. 6). E, no documento final do IX Encontro (ANFOPE, 1998), explicita-se, também, que a base comum é "nacional, poque nos unifica, respeitadas as diversidades dos tempos e dos espaços de formação nas instituições" (ANFOPE, 1998, p. 22).

É preciso destacar, ainda, que é, neste IX Encontro, que a Anfope retoma, de forma mais adensada, a Base Comum Nacional, consolidando-a, em seus princípios, aqui delineados de forma resumida:

a) sólida formação teórica e interdisciplinar sobre o fenômeno educacional e seus fundamentos históricos, políticos e sociais, bem como o domínio dos conteúdos da educação básica, de modo a criar condições para o exercício da análise crítica da sociedade brasileira e da realidade educacional;

b) unidade entre teoria/prática: atravessando todo o curso e não apenas a prática de ensino e os estágios supervisionados, de modo

\footnotetext{
${ }^{5}$ A CONARCFE - Comissão Nacional de Reformulação dos Cursos de Formação de Educadores - teve os seguintes encontros nacionais: I Encontro, Belo Horizonte, 1983; II Encontro, Goiânia, 1986; III Encontro, Brasília, 1988; IV Encontro, Belo Horizonte, 1989; e V Encontro, Belo Horizonte, 1990.
} 
a garantir o trabalho como princípio educativo na formação profissional;

c) gestão democrática: como instrumento de luta contra a gestão autoritária na escola e superação do conhecimento de administração enquanto técnica e compreendida como manifestação do significado social das relações de poder reproduzidas no cotidiano escolar;

d) compromisso social do profissional da educação: contra concepções educacionais obsoletas e com ênfase na concepção sócio-histórica da leitura do real e nas lutas articuladas com os movimentos sociais;

e) trabalho coletivo e interdisciplinar: como eixo norteador do trabalho docente, considerando a vivência e significação dessa forma de trabalho e produção de conhecimento e das formas de construção do projeto pedagógico-curricular de responsabilidade do coletivo escolar;

f) incorporação da concepção de formação continuada: visando ao aprimoramento do desempenho profissional aliado ao atendimento das demandas coletivas da escola;

g) avaliação permanente dos cursos de formação dos profissionais da educação deve ser parte integrante das atividades curriculares e entendida como responsabilidade coletiva a ser conduzida à luz do projeto político-pedagógico de cada curso em questão. (ANFOPE, 1998, p. 12-13)

Nesta perspectiva, anunciamos, também, que este último parágrafo da citação referente à avaliação permanente dos cursos de formação (ANFOPE, 1998) foi, a partir do XIV Encontro Nacional, registrado como letra g, incorporando-se como um dos princípios da Base Comum Nacional (ANFOPE, 2008, p. 9). O que significa que a Anfope vem discutindo esses princípios, que fundamentam a Base Comum Nacional, compreendendo que se trata de "[...] um conjunto de eixos norteadores da organização curricular, entendidos como princípios orientadores das condições de formação que deveriam estar presentes nos processos formativos [...]" (ANFOPE, 2008, p. 7).

Ancorada, assim, nos princípios fundantes da Base Nacional Comum e na compreensão de docência, como base da identidade dos profissionais da educação, a Anfope defende uma concepção de profissionalização, apresentada, no VIII Encontro, que “[...] supõe não só a formação inicial e a continuada, como também a valorização dos profissionais, o que requer condições de trabalho adequadas para o exercício da profissão e o desenvolvimento de uma política salarial unificada" (ANFOPE, 1996, p. 24). E considera, também, que a formação inicial é "[...] que vai habilitar para o ingresso na profissão e deverá garantir um preparo específico, com um corpo de conhecimento que 
permita ao profissional a condução do trabalho pedagógico [...]”' (ANFOPE, 1996, p. 25). Nesta perspectiva, a formação inicial deverá contemplar a:

- qualificação para a docência: condição para a condução do trabalho pedagógico, a partir da relação teoria-prática na aquisição, produção e socialização do conhecimento;

- qualificação político-pedagógica: condição para a prática pedagógica que incluí as relações de poder no interior da escola e na relação escola-comunidade;

- qualificação político-social: condição para a compreensão crítica e questionadora de projetos políticos para a educação e para o compromisso com a construção de um projeto políticosocial, comprometido com os interesses populares. (ANFOPE, 1996, p. 25)

Além disso, no IX Encontro Nacional, referente, ainda, à formação inicial, a Anfope (1998) reafirma a defesa de que "[...] a formação inicial deva ser presencial"; todavia, não descarta que seja realizada a Educação a Distância, desde “[...] que envolvam as Faculdades e/ou Centros de Educação como responsáveis pela formação e preparação dos profissionais e dos materiais didáticos" (ANFOPE, 1998, p. 34). E a este respeito, tece a seguinte consideração:

Esta modalidade de formação inicial deverá ser acatada na medida em que haja um alto percentual de momentos presenciais e os recursos materiais e humanos necessários como bibliotecas, vídeos, outros recursos, para sua realização com qualidade social (ANFOPE, 1998, p. $34)$.

No sentido de uma proposta para a formação continuada, a Anfope, em seu IX Encontro Nacional (1998), retoma o que tinha sido debatido e aprofundado no Encontro anterior (1996):

- constituir direito de todos os profissionais da educação e dever das agências contratantes que deverão criar condições para sua operacionalização;

- ser associada ao exercício profissional do magistério, uma vez que atualiza, verticaliza e complementa conhecimentos profissionais;

- estar fincada nos objetivos do projeto político pedagógico da instituição em que atua o profissional que pretende se aperfeiçoar;

- respeitar a área de conhecimento do trabalho do professor;

- resguardar o direito à especialização permanente do professor: 
- ser um processo de interface com o profissional em serviço, no sentido de tratar os aspectos teóricos em articulação com seus problemas concretos;

- valorizar a produção de saberes construídos no trabalho docentes;

- assumir caráter de especialização ao verticalizar conhecimentos, buscando desenvolver competências para a pesquisa no campo de conhecimento do profissional da educação;

- levar em consideração três níveis: o pessoal, enquanto crescimento profissional; o institucional, da agência formadora e da agência contratante, articulado com organismo que favoreçam o desenvolvimento político; e o nível socioeconômico, à medida que se insere em uma sociedade em contínuo movimento de transformação;

- desenvolver uma política de fixação do profissional na instituição em que ele atua;

- ser uma forma de desmascarar as precárias condições de trabalho e salariais do professor, compreendendo-o como trabalhador intelectual;

- fornecer elementos para a avaliação e reformulação de cursos de formação de profissionais de educação;

- resguardar o direito do profissional da educação e do trabalhador da educação, de intervir na definição das políticas de sua formação, inclusive através de suas organizações sindicais. (ANFOPE, 1996, p. 25-26; ANFOPE, 1998, p. 36)

Para a Anfope (2018), tanto a formação inicial quanto a formação continuada têm que ser entendidas como um "processo permanente", em que se articulem as instituições de educação básica e superior. O que requer "[...] um debate aprofundado no âmbito do planejamento da política nacional de formação de profissionais de educação básica" (ANFOPE, 2018, p. 40).

Para além das concepções de base comum nacional, docência, profissionalização e valorização dos profissionais de educação, de formação inicial e continuada, uma outra perspectiva desenvolvida pela Anfope, em especial, em seu VIII Encontro Nacional (1996), foi o conceito de "redes de alternativas" e/ou "alternativas de redes" (p. 19-23), com a ideia de construção de rede de saberes e de ações para a formação dos profissionais da educação. Para a Anfope (1996, p. 20): “[...] ideia de rede se constrói a partir de alguns princípios básicos, como: o de articulação, o de corresponsabilidade e o de movimento" (grifos nossos). Além disso, considera que esses "[...] princípios não são, assim, somente as estratégias para a formação, mas constituem seu conteúdo, forma e metodologia" (ANFOPE, 1996, p. 20). Ainda, no mesmo documento, a Anfope assume, por um lado, 
que "[...] a base comum nacional é o fio inicial de construção das possíveis redes de formação dos profissionais da educação e é no seu próprio processo de construção permanente que vão sendo construídas redes de propostas alternativas de currículo ao modelo centralizador e hierarquizado proposto pelo governo"; e, por outro, que na construção das redes podem ser "[...] percebidas novas possibilidades de alternativas de redes de formação" (ANFOPE, 1996, p. 21).

O que observamos, nos documentos referentes a cada um dos Encontros Nacionais, é que Anfope busca reflexões coletivas, no sentido de elucidar as concepções que a fundamentam. E, nesta perspectiva, um outro olhar diz respeito às inquietações desses eventos nacionais que deram origem aos diferentes debates, e até no sentido de organizar as ações a partir das discussões realizadas. Dentre essas questões, retomamos algumas, porque, para nós, apesar das mudanças temporais, continuam a nos preocupar e fazer com que busquemos saídas e/ou soluções e/ou formas de resistência ${ }^{6}$ :

- Como responder aos desafios atuais no campo da formação do profissional da educação?

- Que profissional pretendemos formar?

- Como equacionar a complexidade da organização do trabalho escolar e a especificidades das áreas do conhecimento e seu tratamento didático-metodológico? (ANFOPE, 1998, IX Encontro Nacional)

- Como garantir a formação de qualidade? Que princípios de formação devem ser balizadores da atuação profissional? Qual a ética que orienta o exercício profissional dos professores? (ANFOPE, 2000, X Encontro Nacional)

- Que alternativas de resistência temos diante deste quadro? (ANFOPE, 2018, XIX Encontro Nacional)

$\mathrm{E}$, diante dessas e de tantas outras questões frente aos desafios a serem enfrentados, a Anfope, em sua luta, fortalece, também, suas ações, em um movimento de resistência às políticas e reformas brasileiras, a partir da LDB 9.394/96 (BRASIL, 1996) e de outros desdobramentos histórico-sociais e políticos, tais como:

\footnotetext{
${ }^{6}$ Dentre essas formas de resistência, que também circulam em torno de algumas dessas questões, apesar do tempo que já se passou, temos as lives do canal Anfope Nacional, tais como: "As novas DCN para formação de professores: retrocessos e resistências" (15/6/20); "DCN da Formação Continuada de Professores: retrocessos e resistências" (29/06/20); "O papel do FORUMDIR e da ANFOPE na resistência à BNC da formação de professores" (06/07/20); “Que projeto de Formação de Professores queremos?" (20/07/20); "Processos históricos nas disputas pela Formação de Professores!" (27/07/20), entre outras. Disponível no canal da Anfope: https://www.youtube.com/channel/UCT9AtlNzQRhh9cbMM1KZ48Q. Além das lives, a Anfope continua com seus Boletins, que informam a respeito das concepções desenvolvidas pelo Movimento, assim como da agenda de ações e do Plano de Lutas. Os números dos últimos Boletins (de out./2018 a julho de 2020) podem ser acessados pelo site: https://www.anfope.org.br/boletins/.
} 
$1^{\circ}$ Nas discussões anteriores à Lei n. 10.172/2001 (BRASIL, 2001), que instituiu o Plano Nacional de Educação (2001-2010), “[...] mas que não contemplou muitas das proposições indicadas pelo III Congresso Nacional de Educação (CONED), que ocorreu em Porto Alegre/RS, em 1999”' (BRZEZINSKI, 2018, p. 25);

$2^{\circ}$ Nas Diretrizes Curriculares Nacionais do Curso de Pedagogia, aprovadas em 2006, "e que incorporaram muitos princípios e concepções da Anfope" (BRZEZINSKI, 2018, p. 27);

$3^{\circ}$ Nas Conferências Nacionais de Educação (Coneb ${ }^{7}$, 2008; Conae $^{8}, 2010,2014$, e Conape $\left.{ }^{9}, 2018\right)$, que ocorreram após mobilizar estados e municípios, e em que a Anfope teve presença ativa nas várias regiões brasileiras (ANFOPE, 2012; 2014; 2016; 2018);

$4^{\circ}$ Na proposta da construção de um Sistema Nacional Público de Formação dos Profissionais da Educação, que seja "responsável pela institucionalização de uma orientação política comum e de um compromisso permanente do Estado e da sociedade no sentido da garantia do direito à educação" (ANFOPE, 2008, p. $15)$

$5^{\circ}$ No acompanhamento e avaliação da Política Nacional de Formação de Profissionais da Educação Básica e do Plano Nacional de Formação de Profissionais do Magistério da Educação Básica (Parfor), conforme o Decreto n. 6.755/09 (BRASIL, 2009), cuja finalidade foi organizar, em regime de colaboração entre a União e os entes federados, a formação inicial e continuada dos profissionais do magistério para as redes públicas da educação básica (ANFOPE, 2010, 2012, 2016);

$6^{\circ}$ Nos Fóruns Permanentes de Apoio à Formação Docente/Fepad, conforme a política do Parfor e o Decreto n. 6.755/09 (BRASIL, 2009), indicando membros titulares e suplentes em 23 estados e no Distrito Federal. Ainda, relacionado ao Fepad, é preciso destacar que a Anfope desenvolveu, em nível nacional, a pesquisa participante intitulada "Observatório de Formação e Valorização Docente: configurações e impactos da implementação dos Fóruns Permanentes de Apoio à Formação do Magistério", sob a coordenação da Profa. Iria Bzezinski (ANFOPE, 2010; 2012; 2016);

\footnotetext{
${ }^{7}$ Coneb - Conferência Nacional de Educação Básica (2008), cujo tema central versou sobre a construção do sistema nacional articulado de educação ( $2^{\circ}$ mandato do governo Lula - 2007-2011).

${ }^{8}$ Conae 2010 e 2014 são as Conferências Nacionais de Educação. A Conae 2010 ocorreu, de 28 de março a $1^{\text {o }}$ de abril de 2010 (governo Lula), e teve como tema: "Conae: Construindo o Sistema Nacional Articulado: o Plano Nacional de Educação, Diretrizes e Estratégias de Ação". E a Conae 2014, de 19 a 23 de novembro de 2014, apresentou como tema: "O PNE na Articulação do Sistema Nacional de Educação: participação popular, cooperação federativa e regime de colaboração” (governo Dilma, 2011-2016).

${ }^{9}$ Conape é a Conferência Nacional Popular de Educação, que ocorreu, em 2018, tendo em vista que o Decreto executivo, de 26 de abril de 2017, assim como a Portaria n. 577, de 27 de abril de 2017, respectivamente, desconstruíram o calendário da Conae 2018. Desfigurando, também, o Fórum Nacional de Educação (FNE). A Conape, que ocorreu, de 24 a 26 de maio de 2018, em Belo Horizonte, surgiu sob orientação do Fórum Nacional Popular de Educação (FNPE).
} 
$7^{\circ}$ Na participação do Fórum Nacional de Educação e das Conae 2010 e 2014, e quando passou a apoiar o Fórum Nacional Popular de Educação (FNPE), junto com outras entidades científicas, uma vez que o governo de Michel Temer desmontou do Fórum Nacional de Educação (FNE) e inviabilizou a Conae 2018. Entretanto, a Anfope participou, ativamente, da Conape - Conferência Nacional Popular de Educação, realizada em maio de 2018. Destaca-se, também, que, desde 2010, a Anfope vem participando da composição dos Fóruns Estaduais de Educação, assim como, a partir da aprovação do Plano Nacional de Educação 2014-2014 (BRASIL, 2014), torna-se membro de Comissões Permanentes de acompanhamento e monitoramento dos Planos Estaduais de Educação, em diferentes Estados e no Distrito Federal. Ainda, participa em diferentes fóruns estaduais (FEE/FEPE/FEPAD/FORPROF), bem como marcando presença em frentes populares em defesa da democracia e em outros movimentos e espaços coletivos, afirmando, principalmente, uma política global de formação e o direito à educação para todos (ANFOPE, 2010, 2012, 2014, 2016, 2018); e

$8^{\circ}$ Nos processos de resistência, desde sempre, mas principalmente, nos últimos anos, a Anfope tem assumido posições, que se concretizam em ações mobilizadoras, que vão em defesa da formação, profissionalização e valorização dos profissionais de educação como as indicadas a seguir:

a) Em manifestação contrária à Política Nacional de Formação de Professores ${ }^{10}$, lançada em 18 de outubro de 2017, pelo MEC, que teve, sobretudo, como objetivo, promover a adequação dos currículos e propostas pedagógicas dos cursos de formação inicial de professores da educação básica às orientações da Base Nacional Comum Curricular (BNCC), na direção de fortalecer a avaliação individual de estudantes (via SAEB) e de professores (via Exame Nacional de Avaliação do Magistério da Educação Básica/ENAMEB); além de promover o consequente ranqueamento das escolas "produtivas", premiadas e recompensadas como estabelece o PNE, em sua Meta 7, Estratégia 7.36;

b) Em posição contrária à Escola sem Partido", ao "amordaçamento do professor", que ameaça a autonomia do professorado, sua atuação, liberdade de ensinar e aprender e o direito à educação de crianças e jovens (ANFOPE, 2018, p. 31-32). A Anfope (2018), então, mobilizouse, com mais de 383 entidades e coletivos (sindicatos, associações, grupos de pesquisa, departamentos, programas de pós, movimentos sociais, entre outros), assinando, em 09 de julho de 2018, uma "Carta Aberta em Defesa da Educação Democrática" (contra projetos de censura à Educação Nacional);

\footnotetext{
10 Para maiores esclarecimentos, consultar a "Manifestação das entidades educacionais sobre a política de formação de professores anunciada pelo MEC. Disponível em: http://www.anfope.org.br/wpcontent/uploads/2018/05/notadaentidades-20.10.17-contra-politica-forma\%C3\%A7\%C3\%A3o.pdf.

11 Ver a Carta Aberta em defesa da Educação Democrática. Disponível em: http://www.anfope.org.br/wpcontent/uploads/2018/07/CARTA-Aberta-em-defesa-da-EDUCA\%C3\%87\%C3\%83DEMOCR\%C3\%81 TICA.pdf.
} 
c) Ao enfrentar e combater a política de avaliação dos professores, com critérios de desempenho vinculados à lógica meritocrática (Prova Nacional de Concurso para o Ingresso na Carreira Docente) (ANFOPE, 2018);

d) Ao repudiar cortes orçamentários que atingem a educação, ciência e tecnologia, com repercussão nos programas de pós-graduação, de formação de professores, de extensão universitária, de apoio à assistência estudantil, comprometendo não só o desenvolvimento científico e tecnológico, mas também a democratização do acesso e a garantia de permanência no ensino superior (ANFOPE, 2018);

e) Em posição contrária à Base Nacional Comum Curricular ${ }^{12}$ (BNCC) (BRASIL, 2017), tanto para a Educação Infantil e Ensino Fundamental, quanto para o Ensino Médio, devido aos inúmeros problemas, tais como: a padronização curricular, "que tem como fundamentos o lema 'avaliar e punir' estudantes, escolas e professores" (ANFOPE, 2018, p. 29); a minimização de conteúdos e conhecimentos; a adequação automática da formação docente à BNCC; a adoção de material didático previamente estabelecido; o fortalecimento de avalições nacionais censitárias em larga escala; a desvalorização de experiências em espaços não escolares; a concepção redutora do processo de alfabetização e do papel da escola; o esvaziamento do ensino médio; e as propostas de medidas curriculares que autorizam o ensino a distância no ensino médio, entre outros aspectos (ANFOPE, 2018);

f) Ao repudiar, junto com outras entidades acadêmicas e científicas ${ }^{13}$, a associação do Programa de Residência Pedagógica (PRP) e do Programa Institucional de Bolsa de Iniciação à Docência (Pibid) à BNCC, tendo em vista o estreitamento curricular, cujo processo de elaboração, discussão e aprovação tem sido alvo de críticas contundentes, tais como: as avaliações em larga escala, voltadas para a quantificação e padronização dos futuros testes; e a indução, no caso do Ensino Médio, ao privilegiamento de apenas duas disciplinas, com vistas à adequação da BNCC a exames como o PISA (ANFOPE, 2018);

g) Em manifestação contrária às Diretrizes Curriculares Nacionais para a Formação Inicial de Professores para a Educação Básica - da Educação Infantil ao Ensino Médio, denominada BNC - Formação (BRASIL, 2019), que, segundo a Anfope $\left(2019^{14}\right)$, “compromete a elevação da

\footnotetext{
12 Consultar as notas de repúdio "Posição da Anfope sobre a BNCC (11/09/2017) e Nota Anfope-BNCC em 2018 Brasília (14/09/2018), disponibilizadas em: http://www.anfope.org.br/cartas-e-manifestos/.

13 Ver a nota de repúdio "Entidades se posicionam contrárias à padronização e controle impostos pelo Programa de Residência Pedagógica! Não à BNCC!". Disponível em: http://www.anfope.org.br/wpcontent/uploads/2018/05/Manifesto_Programa_Resid\%C3\%AAncia_Pedag\%C3\%B3gica.pdf.

${ }_{14}$ Para maiores esclarecimentos, consulte o site da Anfope: https://www.anfope.org.br/anfope-repudia-aaprovacao-pelo-cne-da-resolucao-que-define-as-novas-diretrizes-curriculares-para-formacao-inicial-deprofessores-da-educacao-basica-e-institui-a-base-nacional-comum-para-a-formacao-in/.
} 
qualidade dos cursos de formação e da educação brasileira, e anula os avanços propostos pela Resolução 02/2015". E, também, a Anfope $\left(2020^{15}\right)$ manifesta-se, contrariamente, às Diretrizes Curriculares Nacionais e Base Nacional Comum para a Formação Continuada de Professores da Educação Básica (BNC-Formação Continuada), conforme Parecer CNE/CP, de 19 de maio de 2020 (BRASIL, 2020) e a Minuta de Resolução CNE/CP, ainda a ser homologado em 2020; e, principalmente,

h) Em defesa da imediata implementação das Diretrizes Curriculares Nacionais de Formação Inicial e Continuada de Profissionais do Magistério, conforme o Parecer n. 2/2015 e a Res. CNE/CP n, 2, de 01/07/2015 (BRASIL, 2015). A Anfope (2018, p. 24) considera os avanços contidos na Res. CNE/CP n, 2/2015, entendendo que: "[...] é urgente e necessária não apenas a defesa da referida Resolução, mas a implementação imediata da Resolução nos processos de reformulação das licenciaturas em todas as IES". E reforça este entendimento, quando participa da "Nota das entidades nacionais em defesa da Resolução 02/2015" (ANFOPE et al., 2019).

Essas quatro últimas posições da Anfope elucidam melhor o campo de lutas necessário para o enfrentamento das políticas, que estão sendo implementadas; mas, sobretudo, da urgência de tomada de posição frente a este cenário que se impõe. Em relação à BNCC, Aguiar e Dourado (2019, p. 34) consideram que seu processo de elaboração é " [...] o carro-chefe das políticas governamentais desenvolvidas pelo MEC, uma vez que, para este órgão, a base poderia se tornar o ponto nodal para uma ampla reforma da educação básica". E, neste sentido, abrangeria, segundo estes autores: “[...] a formalização e a articulação entre currículos escolares, a formação de professores, a gestão da educação e os processos avaliativos" (AGUIAR; DOURADO, 2019, p. 35).

Todavia, como já foi manifestado pela Anfope, entre outras entidades acadêmicas e/ou científicas, a BNCC é autoritária, despreza as diversidades locais e regionais e, principalmente, o respeito aos sujeitos que estão envolvidos no processo educacional (ANFOPE, 2017; ANPED et al., 2018). E, de acordo com Lino (2019, p. 32), “[...] trará consequências graves para os profissionais da educação, sua formação e valorização, pois induz ao esvaziamento e à alienação do fazer docente, reforçando históricos processos de desvalorização". O que implica, ao mesmo tempo, a instauração de um clima conservador e antidemocrático na educação básica e superior e, em especial, na formação de seus profissionais. Trata-se, assim, de um encaminhamento polemizado e favorável aos grupos

\footnotetext{
${ }^{15}$ Consultar o "Posicionamento das entidades nacionais sobre o Parecer e a Minuta de Resolução do CNE que define as Diretrizes Curriculares Nacionais para a Formação Continuada de Professores da Educação Básica e institui a Base Nacional Comum para a Formação Continuada de Professores da Educação Básica (BNC-Formação Continuada)". Disponível em: https://formacaoprofessordotcom.files.wordpress.com/ 2020/06/posicionamento-das-entidades-sobre-o-parecer-e-minuta-res-formacao-continuada-do-cne-28maio-2020.pdf.
} 
privatistas, "[...] interessados em formar um trabalhador que lhes fosse submisso, a partir, portanto, de um currículo próximo do que poderíamos chamar de mínimo e muito distante de uma base curricular que lhe propiciasse formação capaz de desenvolver sua autonomia e criticidade" (BAZZO; SCHEIBE, 2019, p. 673).

Outros pontos de destaque dizem respeito à aprovação da BNC - Formação (BRASIL, 2019), ao instituir a Base Nacional Comum para a Formação Inicial de Professores da Educação Básica, e, também, a atual BNC da Formação Continuada de Professores, apresentada pelo CNE sem consulta à área, como destaca Freitas (2020). Esta BNC - Formação Continuada representa, conforme a autora (2020, s/p), “[...] a segunda parte de um conjunto de normatizações que indicam a intenção de aprofundar a implementação de uma política de formação de professores de caráter tecnocrático, alinhada exclusivamente às competências e conteúdos da BNCC e à lógica empresarial privatista que vem se impondo na educação básica pelos reformadores empresarias".

O que este (des) governo pretende é continuar a defender, como também alertam Bazzo e Scheibe (2019, p. 681), "[...] a manutenção das premissas neoliberais, as quais apostam, ainda, em um capitalismo que cada vez mais revela sua impossibilidade de ordenar uma nação com padrões de igualdade social e de justiça”. Trata-se, assim, de um cenário, que precisa ser debatido e combatido por todos nós, profissionais da Educação, "[...] em prol da defesa dos marcos constitucionais, visando garantir o Estado Democrático de Direito e a defesa histórica da educação básica, pública, laica, gratuita, democrática e de qualidade social para todos e todas", conforme afirmam Aguiar e Dourado (2019, p. 37).

Com efeito, todas essas inquietações, adensadas pela atual crise sanitária por conta da pandemia (Covid-19), e, sobretudo, na contramão das lutas da Anfope (e nossas), fazem-nos lembrar das palavras de Freitas (2012, p. 396), quando afirma que: "Ainda há tempo para o Brasil não implementar tais políticas e evitar mais uma década perdida para a educação brasileira". É o que esperamos e no que apostamos!

Diante desse cenário, a Anfope defende, sobremaneira, a Resolução CNE/CP n. 2 , de $1^{\circ}$ de julho de 2015 , porque ela foi produto de um processo democrático de discussão amplo e teve apoio de diversas entidades acadêmico-científicas e de diferentes setores e segmentos voltados para a educação e formação de professores. Além disso, por representar "[...] o corolário de nossas propostas com a indicação da Base Comum Nacional para todos os cursos de formação dos profissionais da educação integralmente contemplada nas DCN agora ameaçadas" (ANFOPE, 2018, p. 23, grifos do documento).

No enfrentamento desses desafios, que nos jogam a todos em momentos de incertezas e de retrocessos, a Anfope continua com o seu Plano de lutas, definindo, também, suas proposições, que foram reafirmadas, junto com o coletivo presente na 
Conferência Nacional Popular de Educação (Conape), em maio de 2018, em Belo Horizonte: a) garantia das condições de qualidade socialmente referenciada por meio de articulação federativa das políticas educacionais democraticamente construídas e em respeito aos direitos humanos e ao diálogo com os movimentos sociais; b) respeito à diversidade e construção democrática da proposta curricular das escolas, contra a padronização do currículo e o modelo de gestão empresarial nas escolas; c) promoção e viabilização de iniciativas de avaliação institucional participativa, que fortaleça o caráter diagnóstico, pedagógico e formativo de avaliação na educação básica e na educação superior; d) gestão democrática na educação brasileira em todos os níveis, sistemas, instituições e com ampliação da participação popular; e) liberdade de expressão no processo de educação e ensino; ou seja, contra o movimento "Escola Sem Partido" e suas "leis da mordaça"; f) garantia da concepção de educação básica constituída pelas etapas de educação infantil, ensino fundamental e médio, assegurando as especificidades das diferentes modalidades, por meio de políticas de acesso, permanência e gestão, contra a instituição das reformas que o sujeitam qualquer nível, etapa ou modalidade da educação ao mercado; g) constituição de uma educação a distância (EaD) e de cursos com qualidade, contra a comercialização desregulamentada da educação e do ensino; h) valorização dos profissionais da educação (formação, carreira, salários, condições de trabalho) na rede pública e no setor privado, contra a crescente flexibilização nas contratações destes profissionais; i) cumprimento da Lei do Piso Nacional Profissional Nacional e a garantia de Planos de Carreira para todos os trabalhadores em Educação Básica e Educação Superior; j) garantia de financiamento e efetivação das leis para o fortalecimento da educação pública e gratuita, em todos os níveis, etapas e modalidades, contra o congelamento de investimentos decorrente da Emenda 95/2016 ${ }^{16}$; 1) garantia de investimento público exclusivamente para o ensino público, contra o fortalecimento do setor privado com gastos públicos (ANFOPE, 2018).

Essas são algumas das ações de mobilização e resistência da Anfope, que configuram um pouco de sua (nossa) luta a favor de uma política global de formação de profissionais de educação para o nosso país. Consideramos que muitas das questões e proposições teóricas e políticas, aqui retratadas, aproximam-se dos textos que fazem parte deste Dossiê. Tais textos desvendam outros olhares, assim como múltiplas perspectivas em relação aos resultados de pesquisas sobre formação de professores. Olhares e perspectivas que redefinem, por um lado, o campo epistemológico, ao estabelecer aproximações com a realidade complexa; e, por outro, sinalizam para o cenário de riscos e incertezas ao tratarem sobre a imposição de políticas educacionais e seus efeitos na formação e profissionalização docente. Contudo, também é possível identificar condições

\footnotetext{
${ }^{16}$ A Emenda 95/2016, instituída pelo governo Temer, que impõe um teto aos investimentos em educação, saúde, assistência social e, também, aos demais gastos primários do governo federal, limitando por 20 anos o aumento dos gastos públicos, diminuindo, sobremaneira, os investimentos em educação.
} 
de possibilidade de enfrentamento e/ou de superação desses desafios. É o que podemos observar dos resultados que aqui passamos a anunciar.

O primeiro texto "A Resolução CNE/CP n. 2/2019 e os retrocessos na formação de professores", de Suzane da Rocha Vieira Gonçalves, Maria Renata Alonso Mota e Simone Barreto Anadon, tendo como ponto de partida a Res. CNE/CP n. 2/2015, problematiza as Diretrizes Curriculares Nacionais para Formação de Professores, aprovadas pelo Conselho Nacional de Educação, em dezembro de 2019. As autoras denunciam que a implementação dessas Diretrizes, alinhadas com a BNCC e com as políticas de avaliação externa, revelam práticas comprometidas com interesses mercantilistas, de produção de materiais didáticos e de promoção de formação inicial e continuada ofertadas pela iniciativa privada, que desconsideram, assim, o movimento dos educadores, suas experiências, estudos e pesquisas. Ainda, alertam que estas DCN representam um verdadeiro retrocesso para a formação docente, pois privilegiam uma formação tecnicista, padronizada e pragmática.

A seguir, o artigo de Rita de Cássia Prazeres Frangella, "Formação de Professores em tempos de BNCC: um olhar a partir do campo do currículo", discute os sentidos de políticas curriculares e da formação "sob rasura", o que implica, para a autora, a necessidade de se colocar em evidência a perspectiva discursiva, ou seja, o entendimento das políticas como “jogos de linguagem indecidíveis, sempre instáveis”. Neste sentido, o texto questiona o atrelamento da implementação da política curricular à formação de professores, em especial, em tempos de BNCC, ao se referir ao Guia de Implementação da Base (BRASIL, 2020) e suas sete dimensões orientadoras no processo de implementação. E destaca, ainda, que sob uma lógica adaptativa a formação e a docência são sempre alvos de ação para adequação/adaptação, desvelando, assim, tentativas de controle e de regulação, que buscam fixar sentidos. A autora propõe, então, como perspectiva, a necessidade de se desestabilizar significações de modo a que se possam negociar novos sentidos para o currículo, formação e docência.

Para que se retomem novas significações para a docência, o texto de Nilson de Souza Cardoso e Isabel Maria Sabino de Farias, "Qual o conceito de docência? Entre resistências e investigações", realiza um Estado da Questão a respeito da temática referente ao "conceito de docência". A análise evidencia, a partir das 23 produções acadêmicas (artigos, dissertações e teses), entre 2015 a 2019, diferentes olhares e perspectivas sobre o que significa a docência, considerando que este conceito é constituído por múltiplas abordagens, dada a sua peculiaridade relacional e a sua complexidade, abrangência e imprevisibilidade. Entretanto, os autores identificam, de forma mais genérica, uma percepção reducionista da docência, delimitada ao fazer docente; assim como revelam a ausência de uma dimensão política desse conceito. Por último, colocam o acento na dimensão política, para que se assuma uma "consciência de 
docência ampliada", em que o pensar e o fazer pedagógico e político estejam juntos para que seja possível compreender o desenvolvimento profissional docente.

Dando continuidade às pesquisas que pretendem ressignificar questões em torno da docência e da formação para ser professor, o texto "Estudantes de Licenciatura no Brasil: representações sociais sobre o "ser professor no futuro", de Romilda Teodora Ens, Jaqueline Salanek de Oliveira Nagel, Thalita Vianna de Lima e Cassiano Roberto Nascimento Ogliari, apresenta uma análise da relação entre as políticas de formação docente para a educação básica e as representações sociais de estudantes de licenciatura sobre o futuro de "ser professor". Nesta perspectiva, os autores enunciam que os estudantes de Licenciatura sofrem tensões e incertezas provenientes das realidades sociais, econômicas e políticas, em que estão inseridos, e que essas tensões/incertezas ganham mais força, quando os futuros professores se projetam no cenário educacional brasileiro de: precárias condições escolares, baixos salários e desvalorização profissional. Entretanto, apesar das incertezas sobre o futuro na profissão docente, ancoram suas representações nas constantes políticas que definem sua formação e nas crenças de superação de suas condições sociais, culturais e econômicas, que lhes foram impostas historicamente, e nas possibilidades de ascensão social via trabalho e profissão docente.

O texto "As pesquisas sobre ciclos de vida profissional docente: revisão da literatura", de autoria de Kátia Augusta Curado Pinheiro Cordeiro da Silva e Shirleide Pereira da Silva Cruz, tem por objetivo analisar as publicações brasileiras que tratam dos ciclos de vida profissional na carreira docente como um processo de vivências na profissão durante o período de 2006 a 2019. No tratamento dessa temática, as autoras colocam o foco nos seguintes conceitos: ciclo de carreira docente, desenvolvimento profissional, ciclo de vida profissional e no conceito de perejivânie (vivência), indicado por Vygotsky (2010). Destacam que a maioria dos estudos localizados considera a análise do ciclo de vida profissional a partir das subjetividades dos professores, assim como das especificidades do trabalho docente, da educação básica e do ensino superior. A partir das características gerais dos estudos selecionados, tendo em vista a sistematização de convergências, direcionamentos diferentes e perspectivas de aprofundamento, as autoras identificam três eixos de análise: a abordagem bibliográfica, a análise processual do ciclo de vida profissional e o foco em uma dimensão do ciclo. E concluem que os ciclos de vida profissional docente são permeados por desafios, dilemas e conquistas, que repercutem no processo de como o professor se percebe e se sente no ambiente de trabalho e na busca de sua realização pessoal e profissional.

Para tratar, ainda, de desafios e perspectivas no contexto da formação docente, o artigo de Mark Carvalho, intitulado "Uma década de formação de professores pelo Parfor: desafios, lições e perspectivas na conjuntura atual" tece uma retrospectiva histórica sobre a formação docente pelo Parfor, sua inserção junto às redes públicas, ressaltando lições e contradições dessa experiência e destacando alguns entraves que foram agravados, em 
especial, pelas estratégias de desmonte das políticas educacionais atuais. Nesta perspectiva, o texto trata, também, da criação do Fórum Nacional de Coordenadores Institucionais do Parfor/ForParfor, de seus princípios e atividades, e, principalmente, do reconhecimento do Parfor como um programa capaz de contribuir com a ampliação do acesso à formação em nível superior dos docentes em exercício na Educação Básica pública por meio de um esforço colaborativo entre os entes federativos e as Instituições brasileiras.

O próximo texto "Pesquisas sobre formação de professores no Mato Grosso do Sul: o que sinaliza a produção dos Programas de Pós-Graduação em Educação?”, de Andréia Nunes Militão, busca verificar o que tem sido produzido no campo da formação docente por meio de três descritores: formação de professores, formação inicial e formação continuada e termos assemelhados a estes unitermos. Trata-se de uma pesquisa documental, que faz um levantamento nos repositórios de seis programas e nos dados disponibilizados pelo Banco de Teses e Dissertações da CAPES e na Biblioteca Digital brasileira de Teses e Dissertações (BDTD), identificando títulos, resumos e palavraschave. Indicam-se alguns limites, destacando a desatualização e incompletude dos bancos de dados, especialmente, aqueles vinculados aos programas de pós-graduação e a qualidade dos resumos. Por outro lado, registra-se que, decorrente do processo de expansão das universidades públicas no Estado de Mato Grosso do Sul, em especial, na primeira década deste século, a produção da pós-graduação em educação tem sido ampliada; entretanto, apesar da variedade de temas, os resultados obtidos não apresentam a temática da formação docente como objeto de análise.

$\mathrm{Na}$ mesma linha de pesquisa documental, o texto de Raquel Cruz Freire Rodrigues, Márcia Morschbacher e Melina Silva Alves, "Análise da produção científica sobre formação de professores: realidade e possibilidades na área da Educação Física", apresenta resultados de pesquisa referentes às produções científicas da área de Educação Física para a formação de professores, no período de 2014 a 2019, disponíveis no BDTD. As autoras constatam que a formação docente está direcionada, predominantemente, para a compreensão da epistemologia da prática e das pedagogias do aprender a aprender, que assume uma perspectiva hegemônica de formação. Observam, também, que há uma menor incidência da concepção de omnilateralidade na fundamentação das dissertações e teses analisadas. Por fim, centram-se na defesa de um modelo alternativo de formação, que apresente a omnilateralidade como possibilidade de formação humana universal, a Base Comum Nacional da Anfope e a Resolução CNE/CP 02/2015 como referências para a formação docente e a Licenciatura Ampliada como proposição mais avançada para a formação de professores de Educação Física.

$\mathrm{O}$ artigo "O uso de situações-problema como instrumento metodológico em uma pesquisa qualitativa no campo da formação de professores", de Mariana Costa Lopes da Silva e Júlio Emílio Diniz-Pereira, trata de pesquisa no campo de formação docente, que 
coloca o foco no uso das situações-problema como instrumento metodológico. Os autores partem de alguns princípios em comum, que envolvem o ensino como atividade profissional apoiada em um repertório de conhecimentos, a prática profissional como um lugar de formação e produção de saberes e a articulação entre as instituições universitárias de formação e as escolas de educação básica. Destacam o caminho metodológico da pesquisa "Saberes docentes e estratégias de ensino: as trocas entre professores de ensino fundamental", colocando o acento na sistematização de estratégias, validadas por meio da argumentação dos docentes envolvidos para discutir as situações-problema. E indicam que, a partir das discussões frente às situações-problema, foi possível organizar as seguintes dimensões de análise: organização do tempo; organização do espaço; organização da interação professor/aluno; transgressões e incivilidades; e ritmos diferenciados. Para os autores, o uso de situações-problemas como um instrumento metodológico cria um espaço de validação de saberes e de posicionamento dos professores, tendo em vista seus propósitos e ações, contribuindo, assim, para o campo da formação de professores.

Deise Ramos da Rocha, em seu artigo "Pesquisas brasileiras sobre professores iniciantes na carreira: contribuições para o campo da formação de professores", apresenta uma revisão de pesquisas brasileiras que trata dos professores iniciantes na carreira docente. Esta revisão diz respeito às publicações de teses e dissertações no banco de dados do IBICT, aos trabalhos em anais de eventos selecionados (ANPEd, ENDIPE e CongrePrince) e às publicações em periódicos Qualis A e B, que foram analisadas com base nas seguintes categorias: exercício profissional, professor iniciante por especialidade, Programa de Iniciação à Docência, revisão literária, socialização escolar, profissionalidade, condição de trabalho, representações sociais e identidade. O texto mostra, ainda, um mapeamento da quantidade de publicações sobre: o professor iniciante por região, os enfoques metodológicos, os procedimentos e/ou instrumentos de pesquisa utilizados e os autores mais citados. E, dentre os resultados, a autora indica que há muitas lacunas e problemas a respeito do início da carreira docente, destacando a necessidade de que sejam promovidas ações de inserção profissional para os professores iniciantes, e que sejam ampliadas as investigações na área, apesar do conhecimento acumulado.

Na direção de um relato de experiência sobre a Educação e as políticas públicas na América Latina, o texto de Agustín Villarreal, intitulado "A Educação na encruzilhada das políticas públicas na América Latina", trata de uma pesquisa exploratória que pretende, por meio do conceito de "educação na encruzilhada", mapear as discussões que ocorreram na Faculdade de Ciências Sociais da América Latina (FLACSO), na sede da cidade de Quito, Equador; na sede da FLACSO, em Assunção, Paraguai e na Universidade de Manizales, na Colômbia, no âmbito da II Bienal de Infâncias e Jovens. $\mathrm{O}$ autor estabelece pontos de encontro e dissonâncias entre as diferentes experiências em uma perspectiva de compreender as encruzilhadas que afetam o sistema educacional 
latino-americano. O propósito maior é o de desafiar os diferentes atores educacionais a repensarem os temas das reformas políticas educativas, sinalizando que o poder político e o papel do Estado estão relacionados ao público e à educação. Além disso, destaca que o papel do educador, ao implementar um projeto político não escapa do campo político, nem de suas relações com o Estado e com as políticas públicas. Mediante essas questões, o autor conclui que a "educação para a encruzilhada" visa não apenas a buscar caminhos ou possibilidades transversais para a educação; mas, sobretudo, fazer com que os agentes educacionais envolvidos possam refletir sobre suas ações de intervenção no campo político, reavaliando o papel de sua tarefa: transmitir a cultura em um mundo profundamente desigual.

A seguir, o texto "Formação de Professores no Brasil a na América Latina na perspectiva da educação inclusiva", de Maria de Fátima Barbosa Abdalla e de Patrícia Cristina Albieri de Almeida, pretende identificar as oportunidades formativas para a educação inclusiva no Brasil e na América Latina. Trata-se de uma pesquisa desenvolvida junto à Oficina Regional de Educação para América Latina e Caribe/OREALC/UNESCO Santiago (2017-2018), que busca mapear os marcos legais e os padrões curriculares de sete países (Argentina, Brasil, Chile, Colômbia, Guatemala, México e Peru), retratando as políticas educacionais para as pedagogias de inclusão. Além disso, as autoras relatam os dados de pesquisa realizada no Brasil em três instituições da região sudeste (duas universidades públicas e uma privada). A partir do modelo de ações docentes para uma pedagogia de inclusão, o texto oferece pistas sobre se e como o tema da inclusão integra o itinerário formativo do futuro professor, ao delinear desigualdades de oportunidades sociais, culturais e educacionais a partir das diferenças de perfis entre os estudantes. As autoras concluem que a formação docente tem reflexos diretos sobre a educação escolar de novas gerações em um contexto de mudanças sociais complexas, e consideram, também, que é preciso que as instituições formativas assumam seu compromisso social com uma educação justa, igualitária e inclusiva.

O último texto "Matar a tribo para fazer nascer a nação: a (in) vibilização da diferença na formação de professores moçambicanos”, de Hermínio Ernesto Nhantumbo, traz uma análise dos discursos que orientam a formação de professores em Moçambique, com base em políticas educacionais que procuram invisibilizar a diferença. O texto chama a atenção para as línguas nativas e outras manifestações culturais nas políticas de formação docente, que são rasuradas pela imposição arbitrária do português como língua oficial e exclusiva de ensino; assim como pela tendência de se tentar fomentar, em suas políticas, únicas possibilidades de pensar o social. Nesta perspectiva, o autor, ao analisar os três momentos do Sistema Nacional de Educação (SNE), anuncia que o apelo à alteridade/diferença se configura como um dos caminhos possíveis para se pensar o currículo não como único, mas como um devir/diferir. Questiona, então, se não há outras possibilidades de se pensar os projetos nacionais e educacionais fora da lógica da imposição, o que poderia ser um caminho frutífero. Enfim, considera que os ideais 
nacionalistas, prescritivos e homogêneos serviram como pontos de questionamento para argumentar que a formação de professores envolve o descarte de uma perspectiva de identidade, em favor da diferença.

Destacamos, ainda, a necessidade, cada vez mais premente, de se realizarem estudos investigativos para favorecer as discussões acerca das políticas públicas voltadas para a formação de professores e da educação em geral. Com esse propósito, os autores dos artigos, aqui indicados, revisitam concepções, tendências e práticas que revelam questões cruciais a serem debatidas (e, por vezes, combatidas), a fim de que se abram espaços para uma formação diferenciada, crítica e orientada para a construção de espaços de resistência a políticas privatizantes e a práticas tradicionalmente excludentes em favor de práticas mais democráticas.

Por fim, agradecemos a cada um dos autores, que se comprometeram em compartilhar seus estudos e pesquisas, sob diferentes olhares e múltiplas perspectivas, apesar do quadro sombrio que assola o nosso país (e o mundo), e que retrata, como diria Paulo Freire (2000, p. 26), um "[...] palco de confrontações entre forças que reagem ao avanço e forças que por ele se batem". Consideramos, assim, que este Dossiê pode contribuir, de forma instigante, reflexiva e plural no sentido de conferir dignidade e esperança às nossas lutas e um lugar de destaque para a Educação.

\section{Referências}

AGUIAR, M. A. S.; DOURADO, L. F. BNCC e formação de professores: concepções, tensões, atores e estratégias. Retratos da Escola, Brasília, CNTE, v. 13, n. 25, p. 33-37, jan./mai. 2019.

ALMEIDA, R. Bolsonaro Presidente: conservadorismo, evangelismo e a crise brasileira. Novos Estud., CEBRAP. São Paulo, v. 38, n. 01, p. 185-213, jan.-abr. 2019. Disponível em: https://www.scielo.br/pdf/nec/v38n1/1980-5403-nec-38-01-185.pdf. Acesso: 20 jun. 2020 .

ANFOPE. Documento Final do VIII Encontro Nacional da Anfope. Belo Horizonte. De 25 a 28 de julho de 1996. Disponível em: https://www.anfope.org.br/wpcontent/uploads/2018/05/8\%C2\%BA-Encontro-Documento-Final-1996.pdf. Acesso em: 07 de abril de 2020.

ANFOPE. Documento Final do IX Encontro Nacional da Anfope. Campinas: UNICAMP, 1998. Disponível em: https://www.anfope.org.br/wp-content/uploads/2018/ 05/9\%C2\%BA-Encontro-Documento-Final-1998.pdf. Acesso em: 08 maio de 2020.

ANFOPE. Documento Final do XIV Encontro Nacional da Anfope. A Anfope e os desafios de um Sistema Nacional de Formação de Profissionais da Educação. Goiás: Universidade Católica de Goiás, Universidade federal de Goiás, de 22 a 24 de novembro 
de 2008. Disponível em: https://www.anfope.org.br/wp-content/uploads/2018/05/ 14\%C2\%BA-Encontro-Documento-Final-2008.pdf. Acesso em: 10 de abril de 2020.

ANFOPE. Documento Final do XV Encontro Nacional da Anfope. Políticas de Formação Inicial e Continuidade de Profissionais da Educação no contexto dos anos 2000. Caldas Novas/GO, de 21 a 23 de novembro de 2010. Disponível em: https://www.anfope.org.br/ wp-content/uploads/2018/05/15\%C2\%BA-Encontro-Documental-Final-2010.pdf.

Acesso em: 12 abril de 2020.

ANFOPE. Documento Final do XVI Encontro Nacional da Anfope. Políticas de Formação e Valorização dos profissionais da Educação: PNE, Sistema Nacional na CONAE/2014 e Fóruns Permanentes de Apoio à Formação Docente. Brasília, 25 a 27 de novembro de 2012. Disponível em: https://www.anfope.org.br/wp-content/uploads/ 2018/05/16\%C2\%BA-Encontro-Documental-Final-2012.pdf. Acesso em: 12 março de 2020.

ANFOPE. Documento Final do XVII Encontro Nacional da Anfope. Políticas nacionais de Formação no Sistema Nacional de Educação. Base Nacional Comum para a educação básica e a formação de professores. Brasília, 2014. Disponível em: https://www.anfope. org.br/wp-content/uploads/2018/05/17\%C2\%BA-Encontro-Documento-Final-2014.pdf. Acesso em: 01 maio de 2020.

ANFOPE. Documento Final do XVII Encontro Nacional da Anfope. Políticas de Formação e Valorização dos profissionais da Educação: conjuntura nacional avanços e retrocessos. Goiânia: PUC/Goiás e Escola de Formação de Professores e Humanidades/EFPH. Goiânia, 07 de dezembro de 2016. Disponível: https://www.anfope.org.br/wp-content/uploads/2018/05/Doc-FINAL-XVIII-

ENANFOPE-6_3_2017-Coordena\%C3\%A7\%C3\%A3o-Iria.pdf. Acesso em: 05 fev.2020.

ANFOPE. Posição da Anfope sobre a BNCC. Brasília, 11 de setembro de 2017. Disponível em: http://www.anfope.org.br/wp-content/uploads/2018/05/CARTA -deBrasilia_ANFOPE-V-Audiência-Publica-CNE-11.9.2017.pdf. Acesso em: 22 abril 2020.

ANFOPE. Documento Final do XIX Encontro Nacional da Anfope. Políticas de Formação e valorização dos Profissionais da Educação: (Contra) reformas e Resistências. Niterói: Universidade Federal Fluminense (UFF), 2018. Disponível em: https://www.anfope.org.br/wp-content/uploads/2018/11/XIX-Encontro-2018.pdf.

Acesso em: 22 maio de 2020.

ANFOPE. A Anfope repudia a aprovação pelo CNE da resolução que define as novas Diretrizes Curriculares para Formação Inicial de Professores da Educação Básica e Institui a Base Nacional Comum para a Formação Inicial de Professores da Educação Básica (BNC-Formação), em sessão realizada no dia 07 de novembro, sem divulgação. Em um plenário esvaziado, 2019. Disponível em: https://www.anfope.org.br/anfoperepudia-a-aprovacao-pelo-cne-da-resolucao-que-define-as-novas-diretrizes-curricularespara-formacao-inicial-de-professores-da-educacao-basica-e-institui-a-base-nacionalcomum-para-a-formacao-in/. Acesso em: 03 jun. 2020. 
ANFOPE et al. Anfope e várias entidades nacionais assinam nota em defesa da formação de professores e da manutenção e implementação imediata da Res. 2/2015, em 09 de outubro de 2019. Disponível em: http://www.anfope.org.br/anfope-e-varias-entidadesnacionais-assinam-nota-em-defesa-da-formacao-de-professores-e-da-manutencao-eimplementacao-imediata-da-res-02-2015/. Acesso em: 06 jun. 2020.

ANPED et al. Entidades se posicionam contrárias à padronização e controle impostos pelo Programa de Residência Pedagógica! Não à BNCC, 06 de março de 2018. Disponível em Disponível em: http://www.anfope.org.br/wp-content/uploads/2018/05/ Manifesto_Programa_Resid\%C3\%AAncia_Pedag\%C3\%B3gica.pdf. Acesso em: 05 jun. 2020.

BAZZO, V.; SHEIBE, L. De volta para o futuro... retrocessos na atual política de formação docente. Revista Retratos da Escola, Brasília, v. 13, n. 27, p. 669-684, set./dez. 2019.

BRASIL. Constituição da República Federativa do Brasil. Constituição de 1988. Brasília: Senado Federal, 1988.

BRASIL Lei n. 9.394, de 20 de dezembro de 1996, já alterada pela Lei 13.415/2017. Brasília, DF: Presidência da República, 1996 [2017]. Disponível em: http://www.planalto.gov.br/ccivil_03/leis/L9293.htm. Acesso em: 20 de nov. 2020.

BRASIL Lei n. 10.172, de 9 de janeiro de 2001. Aprova o Plano Nacional de Educação e dá outras providências. Brasília. Diário Oficial da União - Seção 1, de 10/01/2001, p. $1,2001$.

BRASI. Decreto n. 6.755, de 29/02/2009. Institui a política nacional de formação de profissionais do magistério da educação básica, disciplina a atuação da coordenação de aperfeiçoamento de pessoal de nível superior. Diário Oficial da União. Brasília, DF, 30 jan. 2009, Seção 1, p. 1.

BRASIL. Lei n ${ }^{\circ} 13.005$, de 25 de junho de 2014. Aprova o Plano Nacional de Educação - PNE e dá outras providências. Diário Oficial da União, Brasília, 26 de jun. 2014. Disponível em: https://www.planalto.gov.br/ccivil_03/_ato2011-2014/lei/113005.htm. Acesso em: 03 ago. 2014.

BRASIL. Conselho Nacional de Educação. Resolução CNE/CP n. 02/2015, de $1^{\circ}$ de julho de 2015. Brasília, Diário Oficial da União, Brasília, seção 1, n. 124, p. 8-12, 02 de julho de 2015.

BRASIL. Resolução CNE/CP n.2, de 22 de dezembro de 2017. Institui e orienta a implantação da Base Nacional Comum Curricular, a ser respeitada obrigatoriamente ao longo das etapas e respectivas modalidades no âmbito da Educação Básica. Diário Oficial da União, Brasília, 22 de dezembro de 2017, Seção 1, p. 41-44.

BRASIL. Conselho Nacional de Educação. Resolução CNE/CP n. 2, de 20 de dezembro de 2019. Define as Diretrizes Curriculares Nacionais para a Formação Inicial de 
Professores para a Educação Básica e institui a Base nacional Comum para a Formação Inicial de Professores da Educação Básica (BNC-Formação). Diário Oficial da União, Brasília, 15 de abril de 2019, Seção 1, p. 46-49.

BRASIL. Ministério da Educação. Conselho Nacional de Educação. Parecer CNE/CP, de 19 de maio de 2020. Diretrizes Curriculares Nacionais e Base Nacional Comum para a Formação Continuada de Professores da Educação Básica (BNC-Formação Continuada). Disponível em: https://formacaoprofessordotcom.files.wordpress.com/2020/05/parecer fcd_cne_maio_2020.pdf. Acesso em 20/06/2020.

BRZEZINSKI, I. (Org.). Políticas de Formação do Magistério: Anfope em movimento. Goiânia: Editora Espaço Acadêmico, 2018.

CONARCFE. Comissão Nacional de Reformulação dos Cursos de Formação do Educador (CONARCFE). Reformulação dos Cursos de Preparação de Recursos Humanos para a Educação. Documento de Belo Horizonte. Belo Horizonte, 21 a 25 de novembro de 1983. Disponível em: https://www.anfope.org.br/wp-content/uploads/ 2018/05/1\%C2\%BA-Encontro-Documento-Final-1983.pdf. Acesso em: 20 abril 2020.

CONARCFE. Comissão Nacional de Reformulação dos Cursos de Formação do Educador (CONARCFE). II Encontro Nacional. Documento Final. Goiânia, agosto de 1986. Disponível em: https://www.anfope.org.br/wp-content/uploads/2018/05/2\%C2\% BA-Encontro-Documento-Final-1986.pdf. Acesso em: 02 jun. 2020.

CONARCFE. Comissão Nacional de Reformulação dos Cursos de Formação do Educador (CONARCFE). V Encontro Nacional. Documento Final. Belo Horizonte, julho de 1990. Disponível em: https://www.anfope.org.br/wp-content/uploads/2018/05/ 5\%C2\%BA-Encontro-Documento-Final-1990.pdf. Acesso em: 04 jun. 2020.

FREIRE, P. Pedagogia da indignação: cartas pedagógicas e outros escritos. São Paulo: editora UNESP, 2000.

FREITAS, H. C. L. A (nova) política de formação de professores: a prioridade postergada. Educ. Soc., Campinas, v. 28, n. 100 - Especial, p. 1203-1230, out. 2007.

FREITAS, H. C. L. BNC da Formação Continuada de Professores é apresentada pelo $C N E$ sem consulta à área. Formação de Professores - Blog da Helena. Publicado em 20/05/2020.

FREITAS, L. C. Os reformadores empresarias da educação: da desmoralização do magistério `destruição do sistema público de educação. Educ. Soc., Campinas, v. 33, n. 119, p. 379-404, abr.-jun. 2012.

LINO, L. A. L. Tempos de crise: cenário atual da educação no Brasil. In: LINO, L. A.; NAJJAR, J. (Org.). Planos de Educação, Democracia e Formação: desafios em crise. Curitiba: Appris, 2019, p. 17-37. 
Recebido em: 01 ago. 2020. Aprovado em: 02 ago. 2020.

* Maria de Fátima Barbosa Abdalla é doutora em Educação pela Faculdade de Educação da Universidade de São Paulo/FEUSP. Pós-doutora em Psicologia da Educação pela PUC/SP. Professora do Programa de Pós-Graduação Mestrado e Doutorado em Educação da Universidade Católica de Santos. Líder do Grupo de Pesquisa/CNPq "Instituições de Ensino: políticas e práticas pedagógicas”. Membro da ANFOPE e pesquisadora associada ao Centro Internacional de Estudos sobre Representações Sociais e Subjetividade em Educação/CIERS-Ed da Fundação Carlos Chagas/FCC - Cátedra UNESCO de Profissionalização Docente.

E-mail: mfabdalla@uol.com.br

http://orcid.org/0000-0001-8290-959X

**Júlio Emílio Diniz-Pereira é doutor em Educação pela Universidade do Estado de Wisconsin, em Madison, Estados Unidos. Professor do Programa de Pós-graduação em Educação da Universidade Federal de Minas Gerais (UFMG). Bolsista de Produtividade em Pesquisa do CNPq - Nível 2.

E-mail: juliodiniz@fae.ufmg.br

htpps://orcid.org/0000-0002-5401-4788 